\title{
RELATIONSHIP BETWEEN MUSCLE TORQUE AND PERFORMANCE IN SPECIAL AND SPECIFIC EXERCISES IN YOUNG WEIGHTLIFTERS
}

\author{
PAULINA SZYSZKA ${ }^{1}$, JANUSZ JASZCZUK ${ }^{2}$, JAROSŁAW SACHARUK ${ }^{1}$, FLORIAN PARNICKI ${ }^{3}$, \\ ADAM CZAPLICKI ${ }^{2}$
}

\author{
Józef Pitsudski University of Physical Education in Warsaw, Faculty of Physical Education and Sport \\ in Biała Podlaska, Department of Sports Theory and Practicel, \\ Department of Biomechanics and Computer Science ${ }^{2}$, \\ Faculty of Tourism and Health in Biała Podlaska, Department of Recreation ${ }^{3}$
}

\author{
Mailing address: Paulina Szyszka, Faculty of Physical Education and Sport in Biała Podlaska, Department \\ of Sports Theory and Practice, 2 Akademicka Street, 21-500 Biała Podlaska, \\ tel.: +48 783823710, fax: +48 83 3428800, e-mail: pszyszka87@gmail.com
}

\begin{abstract}
Introduction. The aim of the current study was to examine the relationship between knee and elbow isometric muscle torque values and the results obtained in special and specific exercises in young weightlifters. Material and methods. The study involved eight young weightlifters (age: $19.9 \pm 4.3$ years; height: $176.8 \pm 10.6 \mathrm{~cm}$; weight: $69.0 \pm 19.7 \mathrm{~kg}$ - pretest, $70.9 \pm 21.6$ - posttest). Their performance put them in the second and third top classes of weightlifters their age according to the Polish norms for weightlifting (the so-called 'national class' and 'first class' in the Polish system, which are lower than the 'international class'). The differences between the values obtained in the first measurement of torque performed at the beginning of the preparation period and those obtained at the beginning of the immediate pre-competition period were compared with the differences in the maximal load lifted in special and specific exercises. Results. The training that the weightlifters underwent during the preparation period caused a significant increase in the relative torque values of the knee extensors $(0.56 \mathrm{Nm} / \mathrm{kg}$ on average, $\mathrm{p} \leq 0.047)$ and those of the elbow flexors $(0.35 \mathrm{Nm} / \mathrm{kg}, \mathrm{p} \leq 0.0002)$. Significant differences $(\mathrm{p} \leq 0.05)$ were observed between the results obtained in all of the special and specific exercises examined. A statistically significant relationship was also found between the changes in relative torque values and the results achieved in special and specific exercises. Conclusions. The regression equations derived in the study can help predict sports performance outcomes based on the results of laboratory tests.
\end{abstract}

Key words: weightlifting, muscle torque, special exercises

\section{Introduction}

Maximal muscle strength has been investigated by many authors [1, 2, 3]. Muscle strength has been analysed, among others, in the context of regaining ability $[4,5]$, health prevention [6], and the assessment of strength capacity and the level of fitness in competitive sports [7-10].

In weightlifting, due to the specificity of the discipline, the level of strength is of prime importance [11, 12]. Assessing the strength capacity of weightlifters and helping them to continually improve their technique makes it possible to plan, implement, and monitor the training process well.

In strength sports, changes in strength are measured using laboratory tests and exercise tests carried out during training. The results of such measurements can be compared with the norms for a given population and with a weightlifter's performance in special and specific exercise. Laboratory tests have been widely used and analysed for many years $[13,14]$.

As far as special and specific exercise tests are concerned, one of the pioneers in this field was Kopański [15], who explored the relationship between the results of the measurement of selected muscle torque values and performance in special exercise in weightlifting. Similar research was conducted by Szyszka et al. [16], who investigated the relationship between peak muscle torque values in isometric conditions and performance in special exercise in weightlifting. The authors found correlations between knee torque and the results achieved in barbell squats by female weightlifters. It is worth mentioning that such studies are seldom carried out, despite the fact that maintaining adequate proportions between special and specialised training in particular periods of the macrocycle helps improve performance in sports, including weightlifting [17].

Muscle strength changes significantly during the various phases of an athlete's sports career. In weightlifting, the moment when an athlete starts training is particularly important, especially if they are to achieve superior results. According to Stone et al. [18], weightlifters should start training at the age of 14-15 years, specific training should be performed at the age of 17-18 years, and the best results are usually achieved at the age of 2327 years. It is worth noting, however, that strength capacity develops differently in women and men. The best age for competitive strength training is $18-25$ years in women and $20-30$ years in men [19], whereas elements of maximal strength training should be implemented in girls aged 12-14 years and boys aged $14-16$ years [20]. There is thus a need to diagnose the strength capacity of young weightlifters.

Training loads implemented during the preparation period determine the results achieved during the competition 
the weightlifter is preparing for. These results can be predicted thanks to analysing the effects of the training using laboratory tests.

Taking into account the above and considering the importance of monitoring weightlifters' progress during specific training, the aim of the study was to determine the impact of the training loads used on the results achieved by young weightlifters in special and specific exercise tests and laboratory tests as well as to explore the relationship between the results of the two types of tests.

\section{Material and methods}

\section{Participants}

The study involved eight young weightlifters (age: $19.9 \pm 4.3$ years; height: $176.8 \pm 10.6 \mathrm{~cm}$; weight: $69.0 \pm 19.7 \mathrm{~kg}$ - pretest, $70.9 \pm 21.6$ - posttest). Their performance put them in the second and third top classes of weightlifters their age according to the Polish norms for weightlifting (the so-called 'national class' and 'first class' in the Polish system, which are lower than the 'international class'). The measurements were performed at the beginning of the preparation period (June 2015) and at the beginning of the immediate pre-competition period (September 2015), that is after the preparation period was completed. Over the course of the period which was examined, the subjects' body mass increased by $1.9 \mathrm{~kg}$.

Prior to the research, the subjects were informed about the purpose of the study and gave their written consent. The research programme was approved by the Senate Research Ethics Committee of the Józef Piłsudski University of Physical Education in Warsaw.

\section{Training}

The subjects completed 135 training sessions and lifted the barbell 5,500 $( \pm 781.3)$ times. The average training volume was $393.2( \pm 97.84)$ tons. Table 1 shows the training volume in particular months of the preparation period as well as the immediate pre-competition period.

Table 1. Training volume in particular months of the preparation and immediate pre-competition periods

\begin{tabular}{|c|c|c|}
\hline Month & Volume [tons] & Period of the training process \\
\hline June 2015 & 90.2 & \multirow{2}{*}{ Preparation period } \\
\hline July 2015 & 112.2 & \\
\hline August 2015 & 106.4 & \\
\hline September 2015 & 84.5 & Immediate pre-competition period \\
\hline
\end{tabular}

Most of the work was performed in July (112.2 tons) at a moderate relative intensity (defined as the percentage of the maximum weight in particular exercises), equal to $68 \%$ of the maximum weight. In September, the training volume was reduced to 84.5 tons, and the relative intensity of the exercise was increased to $82 \%$ of the maximum weight.

Special exercises dominated in the period examined: they accounted for $63.6 \%$ of the total work performed and included snatch exercises $(20.54 \%)$, clean and jerk exercises $(28.40 \%)$, and barbell squats (19.52\%). Specific exercises, which included the technical snatch and technical clean and jerk, constituted $11.7 \%$ of the work performed, whereas general exercises accounted for $24.74 \%$ of the work. The percentages of particular exercises which were implemented during the preparation period are shown in figure 1 .

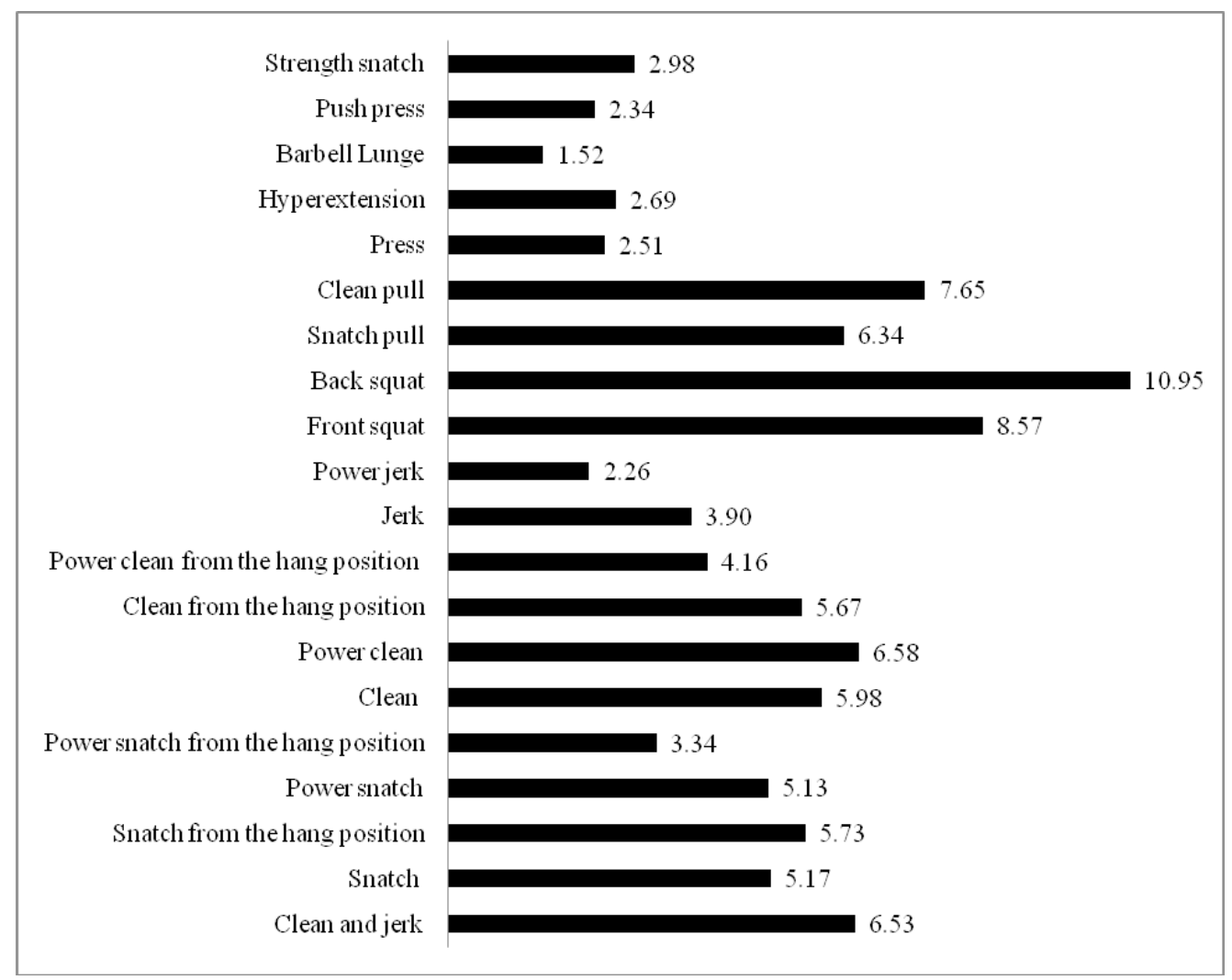

Figure 1. Percentages of particular exercises implemented during the preparation period 
The following exercises included in figure 1 can be classified as special exercises: the technical snatch, the technical clean and jerk, the power snatch, the power clean, the power snatch from the hang position, the power clean from the hang position, the snatch from the hang position, the clean from the hang position, the front squat, and the back squat. During each of the two assessments, the subjects performed these exercises with maximum weight.

The results achieved by the subjects in special and specific exercises were converted into Sinclair points [21].

\section{Measurements}

The strength of the knee flexors and extensors was assessed in isometric conditions on the measuring devices TBK3-P and LR2-P (JBE Staniak, Poland) at the beginning of the preparation period and two days after its completion. The first device makes it possible to measure the torque of the lower extremities and trunk, and the second one allows for the assessment of the torque of the upper extremities (fig. 2). Due to limitations of space and a lack of significant asymmetry in the strength of the limbs, only the data collected for the muscles of the dominant limbs were analysed.

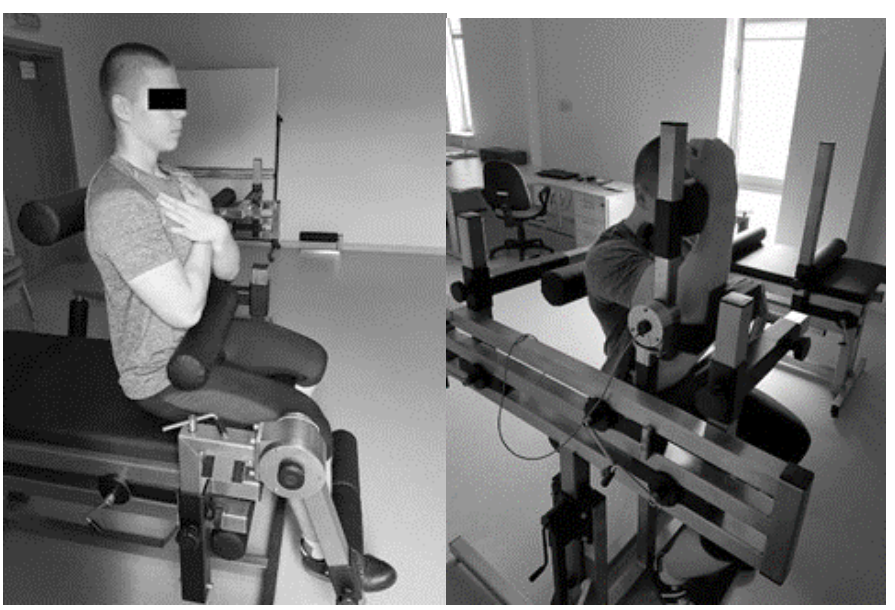

Figure 2. Method of measuring the torque of the knee extensors (right) and elbow flexors (right)

\section{Statistical analysis}

The peak values of the muscle torque measured in isometric conditions and the results achieved in the special and specific exercises were subjected to statistical analysis. The data were first tested for normality of distribution using the Shapiro-Wilk test. Secondly, the differences between mean peak torque values measured at the beginning of the preparation period and those measured at the beginning of the immediate pre-competition period were examined by means of Student's paired t-test. A similar approach was applied to the results obtained in the special and specific exercises. Finally, Pearson's correlation coefficients and regression analysis were used to assess the relationship between the differences in torque values and the differences in maximal load lifted in the exercises studied. All the calculations were made using STATISTICA 12 (StatSoft, Poland).

\section{Results}

The mean increases in the total number of Sinclair points obtained for the special exercises are shown in figure 3.

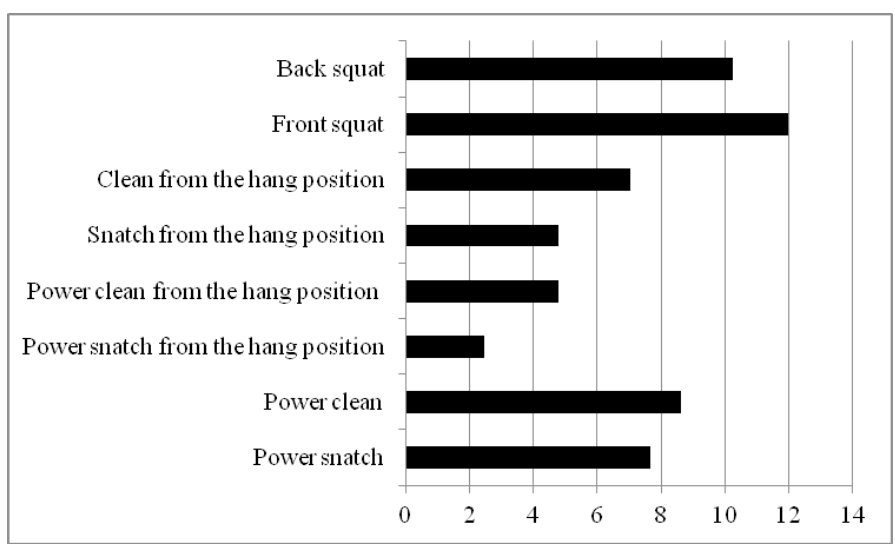

Figure 3. Mean increases in the Sinclair scores obtained in the special exercises

The greatest increase in the subjects' Sinclair scores (by 11.97 points) was found for the front squat, where the weight lifted rose by $10.75 \mathrm{~kg}$ on average, the greatest improvement being $20 \mathrm{~kg}$ (26.91 points). The lowest increase was observed for the power snatch from the hang position: $3.6 \mathrm{~kg}$ or 2.46 points.

As far as specific exercises are concerned, the weight lifted by the subjects in the technical snatch and technical clean and jerk improved by $4 \mathrm{~kg}$ and $5 \mathrm{~kg}$, respectively. The Sinclair scores for these exercises rose by 9 points on average, and the highest increase was 35.36 points.

The changes observed in the peak torque values $(\mathrm{Nm} / \mathrm{kg})$ of the knee flexors and extensors and of the elbow flexors and extensors at the beginning of the preparation period and after its completion are shown in table 2 .

Table 2. Changes in the relative peak torque values generated in the knee and elbow extensors/flexors at the beginning of the preparation period and after its completion

\begin{tabular}{ccccc}
\multirow{2}{*}{ Subject } & \multicolumn{2}{c}{ Knee } & \multicolumn{2}{c}{ Elbow } \\
\cline { 2 - 5 } S1 & Extension & Flexion & Extension & Flexion \\
\cline { 2 - 5 } S2 & 0.40 & 0.24 & -0.26 & 0.25 \\
S3 & -0.21 & -0.61 & -0.04 & 0.34 \\
S4 & 0.73 & -0.02 & 0.11 & 0.61 \\
S5 & 0.54 & 0.26 & -0.06 & 0.29 \\
S6 & -0.12 & -0.86 & -0.49 & 0.15 \\
S7 & 0.58 & 0.12 & -0.20 & 0.33 \\
S8 & 0.75 & -0.35 & 0.00 & 0.34 \\
& 2.09 & 0.41 & -0.01 & 0.48
\end{tabular}

A mean increase of $0.56 \mathrm{Nm} / \mathrm{kg}(\mathrm{p} \leq 0.047)$ was found in the relative torque of the knee extensors. The relative torque values of the elbow flexors also increased significantly $(0.35 \mathrm{Nm} /$ $\mathrm{kg}, \mathrm{p} \leq 0.0002)$, whereas those of the elbow extensors decreased insignificantly by $0.12 \mathrm{Nm} / \mathrm{kg}$ on average ( $\mathrm{p} \leq 0.122)$. 
The statistical analyses showed no significant correlation ( $\mathrm{p}$ $\leq 0.05$ ) between the torque values of the knee flexors and extensors and the results achieved in the technical snatch and technical clean and jerk. Different findings, however, were obtained for the elbow extensors. The changes in the relative torque values generated in these muscles correlated strongly with the increases in the results achieved in the technical snatch $(R=0.79)$ and technical clean and jerk $(\mathrm{R}=0.81)$.

We also determined the relationship between changes in the relative peak torque values generated in the knee and elbow flexors and extensors and those in the results achieved by the subjects in selected special exercises (tab. 3).

Table 3. Pearson's correlation coefficients for the changes in the results achieved in selected special exercises and the relative peak torque values generated in the knee and elbow extensors/flexors

\begin{tabular}{lcccr}
\hline \multirow{2}{*}{ Exercise } & \multicolumn{2}{c}{ Knee } & \multicolumn{2}{c}{ Elbow } \\
\cline { 2 - 5 } & Extension & Flexion & Extension & Flexion \\
\hline Back squat & 0.72 & 0.81 & -0.004 & 0.05 \\
Front squat & 0.44 & 0.47 & -0.32 & -0.24 \\
$\begin{array}{l}\text { Clean from the hang } \\
\text { position }\end{array}$ & 0.86 & 0.83 & 0.41 & 0.60 \\
$\begin{array}{l}\text { Snatch from the hang } \\
\text { position }\end{array}$ & 0.91 & 0.60 & 0.25 & 0.49 \\
$\begin{array}{l}\text { Power clean from the } \\
\text { hang position }\end{array}$ & 0.85 & 0.33 & 0.41 & 0.51 \\
$\begin{array}{l}\text { Power snatch from the } \\
\text { hang position }\end{array}$ & 0.83 & 0.88 & 0.30 & 0.49 \\
$\begin{array}{l}\text { Power clean } \\
\text { Power snatch }\end{array}$ & 0.52 & 0.13 & -0.11 & 0.19 \\
\hline
\end{tabular}

High correlation values were found for the increases in the relative peak torque generated in the knee extensors and those in the results achieved in the snatch from the hang position ( $R$ $=0.91)$ and the clean from the hang position $(\mathrm{R}=0.86)(\mathrm{tab} .2)$. The changes in the relative torque values of the knee flexors correlated strongly with the increases in the results achieved in the power snatch from the hang position $(\mathrm{R}=0.88)$. A lower correlation was found between the changes in the relative torque values of the elbow flexors and extensors and those in the subjects' performance in special exercises. Correlations of $\mathrm{R}=0.60$ and $R=0.41$ were found between the relative torque values of the elbow flexors and extensors, respectively, and the increases in the results achieved in the clean from the hang position.

The following stage of the statistical analysis included only the correlations where Pearson's coefficient was higher than 0.8 and was statistically significant at $\mathrm{p} \leq 0.05$. The power snatch from the hang position was not included in the analysis, due to the fact that it accounted for a low percentage of the exercises performed during the preparation period. This stage of the analysis consisted in using regression functions to model the relationship between the results of laboratory tests and those achieved in special and specific exercises (fig. 4).

The regression function presented in figure 4 makes it possible to predict changes in the Sinclair score based on the changes in relative torque values. The high correlation coefficient $(\mathrm{R}=$ 0.91) for the parameters shown in the graph confirms the validity of this prediction.

Using analogous statistical procedures, we derived equations describing the relationships between:

knee flexor torque and the results achieved in the clean from the hang position

$$
\Delta S=16.515 \Delta M K f+10.64\left(R^{2}=0.68\right),
$$

knee flexor torque and the results achieved in the back squat $\Delta S=15.495 \Delta M E f+15.314\left(R^{2}=0.65\right)$, clean

knee extensor torque and the results achieved in the power

$$
\Delta S=5.632 \Delta M K e+3.143\left(R^{2}=0.72\right),
$$

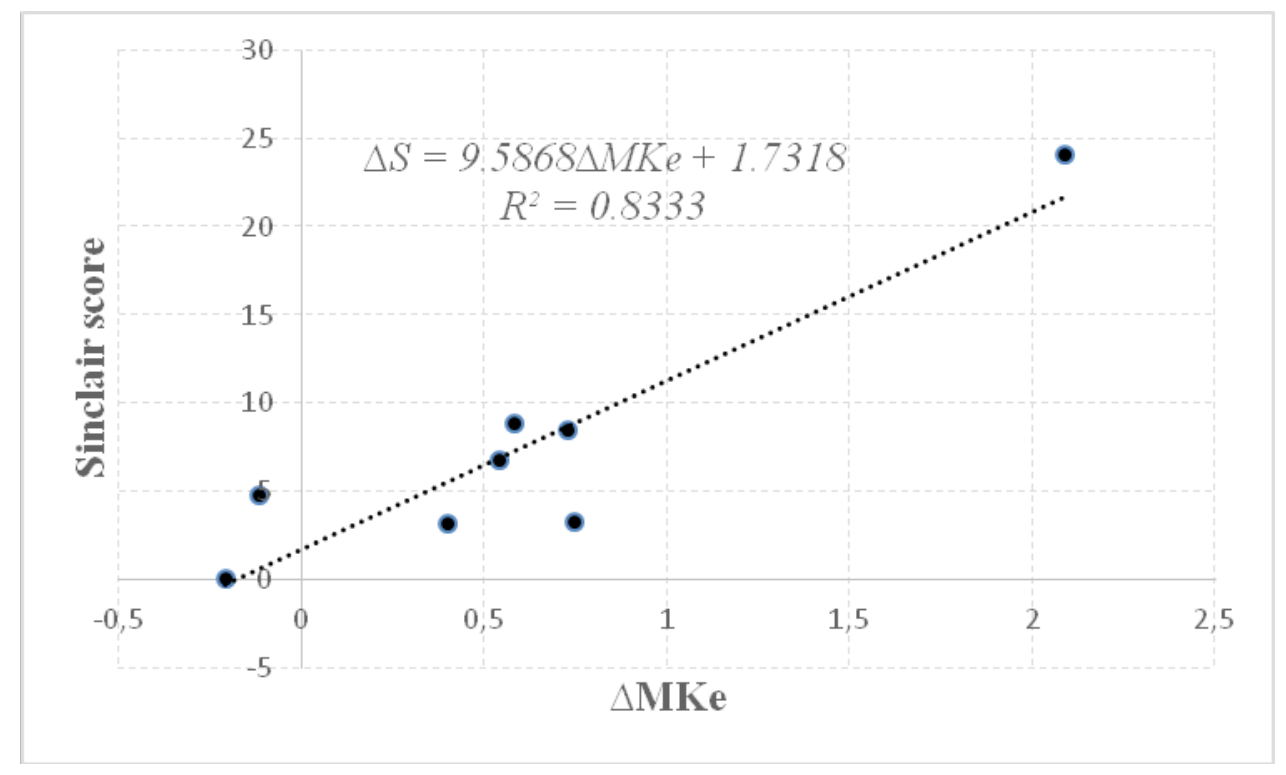

Figure 4. The regression function for the changes in Sinclair scores in the snatch from the hang position and increases in the torque of the knee extensors 
knee extensor torque and the results achieved in the clean from the hang position

$$
\Delta S=11.012 M K e+2.401\left(R^{2}=0.72\right) .
$$

\section{Discussion}

Changes in the isometric strength of the knee extensors in weightlifters over an 8-week-long training period have been investigated by Kopański [15]. The author, however, analysed the absolute values of the increases in muscle torque and in performance in special and specific exercises. As Kopański himself acknowledged, using absolute data may make the analysis problematic, since the weight class of some weightlifters may change during the period that is being examined, which was the case in Kopański's study. This methodological issue makes it difficult to estimate the impact of the increases in body mass on the changes in the results achieved by a weightlifter. The approach applied in this study is based on relative values, which means that changes in body mass did not influence the results of the analysis presented in the study.

The relationship between the torque of the knee flexors and extensors and the results achieved in barbell squatting by female weightlifters was also assessed by Szyszka et al. [16]. The authors observed a statistically significant relationship between these variables in highly trained weightlifters, a finding which was confirmed with regard to a larger group of special and specific exercises in the current study. They also emphasised the fact that establishing normative values in the assessment of the strength capacity of weightlifters should take into account the impact of various factors which are specific for a given group (e.g. body mass).

It is commonly known $[22,23]$ that the muscles which are to the greatest extent responsible for achieving record scores in weightlifting are the extensors of the trunk and upper and lower extremities. Our study has confirmed that performance in specific exercises in the snatch and clean and jerk is influenced more by the strength of the extensors than that of the flexors in the elbow joint, and that mean values of the knee extensors torque increased significantly during the period analysed.

Relationships between pairs of data are often explored using the Pearson product-moment correlation coefficient [24, 25], which is a method we applied in the current study. Apart from calculating Pearson's $\mathrm{R}$, we also used regression equations. The regression functions made it possible to predict changes in the Sinclair score based on changes in relative static torque values. Such analyses can be of practical importance, as laboratory tests can help measure the strength capacity of a given weightlifter. If the weightlifter's performance in special or specific exercises is inferior to the one expected based on laboratory tests, this may indicate deficiencies in technique. Regression equations can thus help predict precise scores in weightlifting exercises based on the results achieved in laboratory tests.

We have identified the strongest correlation between the snatch from the hang position and mean peak isometric torque of the knee extensors. The regression equation explains more than $83 \%$ of the cases studied. This exercise can thus be recommended to verify the results obtained in laboratory tests.

It should be noted that this study examined the results achieved by 8 highly trained weightlifters. In studies which have dealt with similar issues, the number of subjects is often lower. For example, the symmetry of the extremities in 6 weightlifters was assessed by Masoumi et al. [26], and the author emphasised the importance of performing individual analyses in weightlift- ing. We support this approach; however, it was our goal to determine more general relationships in the data, which would not have been possible had we analysed the data for each weightlifter individually.

\section{Conclusions}

The training loads and exercises used in the preparation period improved the weightlifters' performance in special and specific exercises.

A statistically significant relationship was found between the changes in the relative torque values generated in the extensors and flexors in the knee and elbow joints and changes in the results achieved in special and specific exercises.

The regression equations used in the study can help predict sports performance outcomes based on the results of laboratory tests.

\section{Acknowledgements}

The work has been supported by the Polish Ministry of Science and Higher Education under Grant No. 0045/RS3/2015/53 for the years 2015-2018. The experimental data were obtained in the Laboratory of Biomechanics and Kinesiology in the Regional Centre of Research and Development in Biała Podlaska. The Centre was co-financed under the European Regional Development Fund, Operational Programme Development of Eastern Poland 2007-2013.

\section{Literature}

1. Gannon E.A., Stokes K.A., Trewartha G. (2016). Strength and power development in professional rugby union players over a training and playing season. International Journal of Sports Physiology and Performance 11, 381-387.

2. Viljanen T., Viitasalo J.T., Kujala U.M. (1991). Strength characteristics of a healthy urban adult population. European Journal of Applied Physiology and Occupational Physiology 63, 43-47.

3. Wychowański M., Biernat R., Witke A. (2013). Assessment of healthy students' locomotion in a wheelchair. Polish Journal of Sport and Tourism 20(4), 243-248.

4. Czaplicki A., Jarocka M., Walawski J. (2015). Isokinetic identification of knee joint torques before and after anterior cruciate ligament reconstruction. Plos One 10. DOI: 10.1371/journal.pone.0144283.

5. Karnikas K., Arampatzis A., Brüggemann G.P. (2009). Motor task and muscle strength followed different adaptation patterns after anterior cruciate ligament reconstruction. European Journal of Physical and Rehabilitation Medicine 45, 37-45.

6. Häkkinen A., Kauhanen H. (1986). A biomechanical analysis of selected assistant exercises in weightlifting. Journal of Human Movement Studies 12, 271-288.

7. Appleby B., Newton R.U., Cormie P. (2012). Changes in strength over a 2 -year period in professional rugby union players. Journal of Strength and Conditioning Research 26, 2538-2546.

8. Buśko K., Nowak A. (2008). Changes of maximal muscle torque and maximal power output of lower extremities in 
male judoists during training. Human Movement Science 9, 111-115.

9. Śliwa M., Sacewicz T. (2015). Biomechanical assessment of the strength of volleyball players in different stages of the training macrocycle. Polish Journal of Sport and Tourism 22(3), 148-152.

10. Wisloff U., Helgrund J., Hoff J. (1998). Strength and endurance of elite soccer players. Medicine $\mathcal{E}$ Science in Sports $\mathcal{E}$ Exercise 30, 462-467.

11. Enoka R.M. (1979). The pull in Olympic weightlifting. Medicine and Science in Sports 11, 131-137.

12. Garhammer J. (1989). Weightlifting and training. In C.L. Vaughan (ed.), Biomechanics of sport (pp. 169-211). Boca Raton: CRC Press.

13. Jaric S. (2001). Muscle strength testing. Use of normalisation for body size. Sports Medicine 32, 615-631.

14. Jaszczuk J., Wit A., Trzaskoma Z., Iskra L., Gajewski J. (1988). Biomechanical criteria of muscle force evaluation in the aspect of top-level athletes selection. Biology of Sport 5, 51-64.

15. Kopański R. (1991). Impact of load on static strength in weightlifters. Poznań: Monografie AWF. [in Polish]

16. Szyszka P., Sacharuk J., Jaszczuk J. (2011). Static strength of flexor and extensor muscles of knee joint - results achieved in squatting by female weightlifters during preparation period. Collection of post-conference materials. Weightlifting, fitness for all sports: Benefits of Olympic weightlifting for strength and conditioning, October 29, 2011. Bratislava: ICM Agency.

17. Häkkinen A., Sokka T., Kotaniemi A., Hannonen P.A. (2001). Randomized two-year study of the effects of dynamic strength training on muscle strength, disease activity, functional capacity, and bone mineral density in early rheumatoid arthritis. Arthritis \& Rheumatology 44, 515-522.
18. Stone M.H., Stone M.E., Sands W.A. (2007). Principles and practice of resistance training. Champaign, IL: Human Kinetics.

19. Trzaskoma Z. (2003). Maximal muscle strength and maximal power of women and men in competitive sports. Warszawa: Monografie AWF. [in Polish]

20. Gosser M., Starischka S., Zimermann E. (1993). Fitness training. München: BVL Sportwissen. [in German]

21. Alberta Weightlifting Association. (2001). Sinclair coefficients. Affiliated with the C.W.F.H.C. and I.W.F.

22. Vorobyew A.N. (1978). A textbook on weightlifting. Budapest: International Weightlifting Federation.

23. Kipp K., Redden J., Sabick M.B., Harris C. (2012). Weightlifting performance is related to kinematic and kinetic patterns of the hip and knee joints. Journal of Strength and Conditioning Research 26, 1838-1844.

24. Kim S.-H., Kwon O.-Y., Park K.-N., Jeon I.-C., Weon J.-H. (2015). Lower extremity strength and the range of motion in relation to squat depth. Journal of Human Kinetics 45, 59-69.

25. Suchomel T.J., Sato K., DeWeese B.H., Ebben W.P., Stone M. H. (2016). Relationships between potentiation effects after ballistic half-squats and bilateral symmetry. International Journal of Sports Physiology and Performance 11, 448-454.

26. Masoumi S., Shalmanov A.A., Lukunina E.A. (2015). Asymmetry of strength-speed capabilities in knee muscles and movement in clean and jerk in highly-skilled weightlifters. Teoriya i praktika fizicheskoy kultury 11, 78-80.

Submitted: July 29, 2016

Accepted: August 8, 2016 